\title{
Manifestação de violência no ambiente universitário: o olhar de acadêmicos de enfermagem
}

\author{
Expressions of violence in the university environment: the view of nursing students
}

Manifestación de violencia en el ámbito universitario: visión de estudiantes de enfermería

Zeyne Alves Pires Scherer ${ }^{1}$, Edson Arthur Scherer ${ }^{2}$, Paloma Tamaris Rossi ${ }^{3}$, Kelly Graziani Giacchero Vedana ${ }^{4}$, Luciana Aparecida Cavalin ${ }^{5}$

\footnotetext{
${ }^{1}$ Enfermeira, Doutora em Enfermagem Psiquiátrica. Professora Doutora da Escola de Enfermagem de Ribeirão Preto da Universidade de São Paulo

(EERP/USP). Ribeirão Preto, SP, Brasil. E-mail: scherer@eerp.usp.br.

2 Médico, Doutor em Patologia Experimental. Médico Psiquiatra do Hospital das Clínicas da Faculdade de Medicina de Ribeirão Preto da USP. Ribeirão Preto,

SP, Brasil. E-mail: eascherer@hcrp.fmrp.usp.br.

${ }^{3}$ Enfermeira. Ribeirão Preto, SP, Brasil. E-mail: paloma.rossi@usp.br.

${ }^{4}$ Enfermeira, Doutora em Enfermagem Psiquiátrica. Professora Doutora da EERP/USP. Ribeirão Preto, SP, Brasil. E-mail: kellygiacchero@eerp.usp.br.

${ }^{5}$ Psicóloga, Mestre em Enfermagem Psiquiátrica. Psicóloga do Instituto Federal de São Paulo, UNED Sertãozinho. Sertãozinho, SP, Brasil. E-mail:

lucavalin@bol.com.br.
}

\section{RESUMO}

Estudo qualitativo, descritivo, exploratório que investigou a percepção de estudantes de enfermagem sobre as formas de manifestação de violência no ambiente universitário. Para a coleta de dados, utilizou-se entrevista semiestruturada. Os dados submetidos à análise de conteúdo, modalidade temática, permitiram construir três categorias: "violência interpessoal nos relacionamentos estabelecidos no curso", "participação como vítima ou perpetradora" e "razões para a ocorrência da violência". Os achados destacam desigualdades nas relações de poder e ocorrência de diferentes tipos de violência e tendência na naturalização desses. Os resultados apontam necessidade de criação de sistema que facilite a denúncia de abusos e ofereça apoio às vítimas; investimento em programas de intervenção que conscientizem sobre o tema, melhorem as relações acadêmicas e previnam maus-tratos; inclusão do tema violência nos currículos.

Descritores: Violência; Educação Superior; Educação em Enfermagem; Estudantes de Enfermagem; Saúde Mental.

\section{ABSTRACT}

The aim of this qualitative descriptive exploratory study was to investigate the perception of nursing undergraduate students on the forms of expression of violence in the college environment. Data were collected using semi-structured interviews. The collected data were submitted to the thematic content analysis, and led to the construction of three categories: "interpersonal violence in the relationships established in the course", "participation as a victim or perpetrator" and "reasons for the incidence of violence". The findings highlight inequalities in the relationships of power, the incidence of different types of violence and the tendency to naturalize them. Results point to the need to create a system to make it easier to report cases of abuse and offer support to the victims; to invest in intervention programs to raise awareness on the subject, improve academic relationships and prevent mistreatment; and to include the violence subject in the course program.

Descriptors: Violence; Education, Higher; Education, Nursing; Students, Nursing; Mental Health.

\section{RESUMEN}

Estudio cualitativo, descriptivo, exploratorio, investigando la percepción de estudiantes de enfermería sobre los modos de manifestación de violencia en el ámbito universitario. Datos recolectados mediante entrevista semiestructurada. Los mismos fueron sometidos a análisis de contenido, modalidad temática. Tales datos permitieron la construcción de tres categorías: "violencia interpersonal en relaciones establecidas en el curso", "participación como víctima o victimario" y "razones para que suceda la violencia". Los hallazgos destacan desigualdades en las relaciones de poder y la ocurrencia de diferentes tipos de violencia, así como su tendencia a la naturalización. Los resultados determinan la necesidad de creación de un sistema que facilite la denuncia de abusos y ofrezca apoyo a las víctimas; inversión en programas de intervención que con concienticen sobre la temática, mejoren las relaciones académicas y prevengan los malos tratos; inclusión del tema "violencia" en los programas curriculares.

Descriptores: Violencia; Educación Superior; Educación en Enfermería; Estudiantes de Enfermería; Salud Mental. 


\section{INTRODUÇÃo}

A violência nas últimas décadas passou a ser objeto de estudo de pesquisas científicas e de discussão permanente por parte da sociedade. Uma das situações que tem merecido crescente atenção é a violência no local de trabalho. Qualquer categoria profissional, em quase todos os setores, pode ser acometida. No setor da saúde devido às características do serviço prestado e do ambiente de trabalho, os trabalhadores estão sujeitos a pressões por reformas, necessidade de dedicação em jornadas e turnos longos de trabalho e desmoralização(1).

Aliado a isso, o resultado do aumento da violência doméstica e das ruas está se estendendo as instalações de saúde. Como consequência desta violência generalizada ocorre a deterioração da qualidade de cuidados prestados e os profissionais acabam abandonando suas funções, o que pode resultar em redução dos serviços e aumento dos custos da saúde. Frente a esta realidade, em 2002, o Escritório Internacional do Trabalho, o Conselho Internacional de Enfermeiros, a Organização Mundial da Saúde e Serviços Públicos Internacionais desenvolveram em conjunto o "Manual de orientações para abordar a violência no local de trabalho no setor da saúde", o qual fornece importantes estratégias para lidar com a violência(1).

As instituições de ensino, por sua vez, têm papel importante na sociedade ao constituírem espaço de educação, socialização e formação profissional dos indivíduos. O ajustamento do estudante ao ambiente acadêmico é um processo complexo, multidimensional e multifacetado, construído no cotidiano das relações estabelecidas entre aluno e instituição, que pode ser incrementado ou prejudicado. As instituições de ensino superior, em particular, se encontram imersas em um sistema educacional atrelado a valorização da autoafirmação manifestada nas relações de poder, controle e dominação (padrões predominantes em nossa sociedade), com base no comportamento competitivo e coercivo em detrimento da cooperação. Se no espaço universitário ocorrer a reprodução de desigualdades sociais entre alunos, professores e demais profissionais, pode ser facilitada a ocorrência de violência, muitas vezes vista como comportamento natural e frequentemente desvalorizada ou ignorada ${ }^{(2-3)}$.

Dentre os profissionais da área da saúde, os enfermeiros estão frequentemente expostos a situações de violência em seu local de trabalho, o que traz consequências negativas em seu desempenho. Ocupam a primeira posição no ranking de vítimas desse tipo de violência, comparado com outras profissões da área da saúde. Algumas chegam ao abandono da carreira. A literatura tem mostrado que desde o início de sua formação, enquanto estudantes de graduação em enfermagem, são vítimas de diferentes atos de agressão $^{(1,4-6)}$.

$\mathrm{Na}$ instituição universitária, a afetividade na relação professor-aluno e as formas de controle exercidas podem facilitar o preparo do estudante para lidar com as exigências e responsabilidades profissionais. Por outro lado, atitudes coercitivas, percebidas como violências, podem resultar em prejuízos no desenvolvimento do aprendiz, manifestados em desinteresses, diminuição da disposição de aprender e atuar, absenteísmos, atrasos, desistências e produção de sintomas de ansiedade e depressão ${ }^{(7-8)}$.

Desta forma questionamos como têm ocorrido as relações estabelecidas entre professores-alunos, profissionais-alunos e alunos-alunos? Os estudantes conseguem identificar os tipos de violências que ocorrem no ambiente acadêmico? Quais as consequências sobre seu aprendizado, desempenho profissional e sua condição de saúde (física e mental)?

Neste sentido, conhecer o que alunos de graduação em enfermagem sabem ou vivenciaram acerca da violência em diferentes ambientes da universidade, pode fornecer material para melhor entender a forma como ela acontece. Assim como, esclarecer os objetivos que a subjazem, para que seja possível desenvolver nos futuros profissionais as competências ou habilidades necessárias para lidar com a realidade social com a qual se defrontarão, ou seja, atuação nos serviços de saúde no reconhecimento, assistência e acolhimento as vítimas de violência.

Diante do exposto, neste estudo investigamos a percepção dos de acadêmicos de enfermagem sobre as diferentes formas de manifestação de violência no ambiente universitário.

\section{MÉTODO}

Pesquisa descritiva exploratória com abordagem qualitativa $^{(9)}$, da qual participaram 13 estudantes do sexo feminino, solteiras, com faixa etária entre 20 e 31 anos, cursando o terceiro ano do curso de bacharelado em enfermagem de uma instituição de ensino superior pública do interior do estado de São Paulo, Brasil.

A seleção das participantes foi aleatória. A partir da lista de frequência da turma do terceiro ano (total de 76 alunos), utilizamos o critério da progressão aritmética de razão cinco contado a partir do primeiro nome desta lista. Quando alguma das selecionadas não aceitou participar 
do estudo foram selecionadas as estudantes em posição imediatamente posterior ou anterior da lista, respectivamente. A definição desta amostra intencional foi fundamentada na técnica do fechamento por saturação teórica ${ }^{(10)}$, ou seja, a inclusão de novos participantes foi suspensa quando os dados obtidos mostraram-se redundantes ou repetitivos e não acrescentavam informações relevantes para a compreensão do fenômeno em estudo. A escolha por alunos do terceiro ano do curso foi por estes terem maior vivência da jornada acadêmica e contatos com a profissão. Não houve critério de exclusão.

Para coleta de dados utilizamos uma entrevista semiestruturada ${ }^{(9)}$ previamente elaborada e submetida à apreciação de três juízes. As questões continham dados de identificação dos participantes e o conhecimento destes sobre violência e sua ocorrência no contexto escolar universitário. Os sujeitos foram entrevistados no período de junho a setembro de 2010 em sala reservada e horários combinados, sem comprometer a participação nas atividades acadêmicas. O tempo de aplicação de cada entrevista variou de 20 a 45 minutos.

As entrevistas foram gravadas e, posteriormente, transcritas e submetidas à análise de conteúdo, modalidade temática(11). Fizemos a leitura do material procurando identificar as unidades de significação, definindo-as em categorias conceituais segundo reagrupamento analógico e, na sequência, articulamos o material empírico com a literatura.

Para oferecer uma visão representativa dos conteúdos estudados e fundamentar a discussão apresentamos trechos das entrevistas, identificados pela letra " $E$ " de entrevista seguida pelo número correspondente a ordem em que foram realizadas. Esse procedimento teve o intuito de garantir o anonimato dos sujeitos.

O projeto que deu origem a pesquisa foi aprovado pelo Comitê de Ética e Pesquisa da instituição investigada (Protocolo 1033/2009) e todas as participantes assinaram o termo de consentimento livre e esclarecido.

\section{RESULTADOS E DISCUSSÃO}

As 13 estudantes entrevistadas identificaram a ocorrência de violência psicológica interpessoal no curso que frequentam. Destas, quatro mencionaram, também, episódios de violência física e uma de negligência autoinfligida. A análise de conteúdo do material transcrito possibilitou a identificação de categorias empíricas que se configuraram como grandes temas de análise. Assim, as três categorias foram: "violência interpessoal nos relacionamentos estabelecidos no curso", "participação como vítima ou perpetradora" e "razões para a ocorrência da violência". Estas foram descritas e exemplificadas com trechos extraídos dos discursos das estudantes entrevistadas.

\section{Violência interpessoal nos relacionamentos estabelecidos no curso}

Do total de participantes, sete referiram ter presenciado situações de violência envolvendo colegas e seis mencionaram que apenas ouviram relatos. Citaram professores, profissionais em campos de estágio e colegas como perpetradores.

O ambiente universitário é diferente do que os estudantes tiveram contato em sua formação anterior, no ensino fundamental e médio. Na universidade o aluno fica mais próximo do que será sua vida profissional e, consequentemente, é exposto a cobranças, pressões e exigências maiores, tanto pelos professores e outros profissionais envolvidos no ensino, quanto pelos colegas e por si próprios ${ }^{(8)}$.

As alunas relataram a ocorrência de trotes, chacotas, xingamentos, insultos, ofensas, atitudes de menosprezo e, até mesmo, agressão física. Como resultados destas diferentes manifestações de violência podem surgir comportamentos de exclusão ou de evitar contato, tanto por parte do agressor quanto da vítima. Estes achados corroboram a literatura acerca da violência entre pares em instituições de ensino superior, onde é visto que as vítimas de trotes, mesmo o solidário, o toleram para não ficarem antipatizados e que estudantes do sexo feminino costumam agredir de forma indireta, espalhando rumores (fofocas), ou excluindo socialmente ${ }^{(5,12)}$.

Tem a violência verbal, os trotes também que acabam sendo uma forma de violência. (E9)

Ouvi relatos de violência verbal em sala de aula. Aluno xingando outro aluno, sabe, tirando sarro, a pessoa pensou que a outra não se importou, mas você vê que a pessoa ficou meio incomodada com o insulto. (E5)

Entre os alunos, a pessoa já vem com voz alterada, tom de voz alterado, palavras que não são normais no cotidiano, que ofendem a pessoa mesmo. (E8)

Eu acho que há violência moral através de ofensas por palavras entre colegas. (E12)

Já presenciei humilhação entre alunos, de falar que a pessoa tava mais gordinha de um jeito que agride. Tem, também, uma colega que cada vez que vai falar tem sempre um cochicho: "De novo! Nossa, desse jeito eu não vou conseguir sair da sala! Não vai terminar nunca!" Um dia ela olhou para trás e ouviu. Foi uma situação chata. 
Ela engoliu a pergunta, não perguntou. Nunca mais a vi levantar a mão para perguntar. (E1)

Acredito que há a violência física entre estudantes, acontece muito em festas. Às vezes a gente percebe que tem um pessoal que acaba extravasando um pouco na bebida, que pode colocar pra fora tudo o que ele esta sentindo e acaba usando de violência, agressão física, psicológica. (E7)

A literatura científica tem mostrado que estudantes em seus primeiros contatos com a prática em estágios clínicos são vítimas de abuso verbal e acadêmico, sentindo-se oprimidos e confrontados pelos docentes ${ }^{(3,13-}$ 14). Tais situações podem ser consideradas como abuso de poder, de degradação, tem caráter de humilhação e tendem a ser expressos de forma pública, diante de outros, rebaixando as capacidades da vítima e ridicularizando sua identidade ${ }^{(5)}$. A forma de tratamento, expressa na comunicação pode criar barreiras na relação empática, tão necessária para a proteção, o cuidado e o desenvolvimento do aluno, tornando o ambiente escolar, muitas vezes, um espaço frustrante e inadequado para um processo de ensino e aprendizagem significativo(15-16). Além disso, a percepção de determinado professor como agente punidor, pode levar os alunos a evitar contato com o mesmo, aumentando absenteísmos, atrasos e, mesmo desistências ${ }^{(8,17)}$.

A hierarquia, acho que é um modo de violência. Como os professores tratam os alunos aqui dentro da universidade, acho que afeta muito o mental do aluno. Vai influenciar como ele vai progredir nas atividades acadêmicas. Caso que eu considerei uma violência foi com uma aluna que fazia estágio. Ela foi pegar a luva e a professora agarrou no braço dela e começou a gritar no meio do corredor, se ela era dona ou o pai dela era dono de fábrica de luvas. Ela estava gastando luvas, ela achava que ali era o que? Como que um aluno vai voltar no outro dia para um estágio? Como vai continuar as atividades de estágio, cuidar de um paciente? Ele vai estar super mal, o psicológico dele vai estar super afetado. Para mim isso é o cúmulo do absurdo, um professor graduado fazer isso com aluno. Ele sabe que isso é um modo de violência? Eles não são pessoas letradas, estudadas? Nossa, ridículo! (E4) Violência verbal expressa pelos professores através do autoritarismo com alunos. Eu acho que isso deprime muito o aluno. (E9)

Já vi professores chamando alunos de menina, filhinho, lerdinha que eu considero meio pejorativo. (E13)
Quando tem aquelas conversinhas entre alunos, tem professor que fica meio nervoso e acaba repreendendo, não de forma tão positiva, mas de humilhar o aluno. $O$ professor te coloca lá em baixo. Fica chato pro aluno quando é repreendido desta forma. Aluno que dorme e professora tira um sarro. (E2)

Eu presenciei violência psicológica. A gente estava num laboratório de ensino, aprendendo a coletar sangue. A professora falou: não é assim, você esta fazendo errado, não é desse jeito. Você não é competente, você não deveria estar nesta área, deveria escolher outra profissão. Puxou da mão da colega e ela começou a chorar no laboratório, no meio de todo mundo. Não foi só com ela, foi com outros alunos também. Achei um jeito meio grosso e não precisava ter falado isso. Deu pra perceber que a professora não estava nem aí, não importava se você estava nervosa, se estava errada, se não sabia fazer. Você se sente uma incompetente. Depois que a aluna começou a chorar a professora foi pedir desculpas. (E5)

Uma colega em estágio era um pouco lenta para pegar segurança no que fazia. Acredito que ela seja assim até hoje, mas é o jeito dela, ela demora mesmo. Ela estava com uma dificuldade de aplicar uma intramuscular num paciente muito emagrecido. A professora ficou apressando pra fazer tudo rápido. Ela ficou muito nervosa e fez rápido demais aí a professora puxou a orelha dela, não sei se foi com força, não sei o que ela sentiu fisicamente. Mas foi tudo na frente do paciente. Eu achei uma coisa errada, porque se você quer repreender o aluno, você repreende em outro lugar, longe do paciente. Foi muito constrangedor, fiquei com vergonha pela professora e pela minha colega na frente do paciente. Eu sei que era pressão mesmo, tortura psicológica. Minha professora, também humilhava pra caramba os alunos, caso eles errassem. Era tudo aluno bom. (E6)

Eu já presenciei professores numa situação que não era adequada falando assim: ah, porque você nunca vai conseguir aprender isso, você até hoje não melhorou, você nunca vai conseguir melhorar, constrangendo o aluno, deixando-o extremamente perdido, envergonhado. Acredito que isso é uma forma de violência psicológica muito grave. Tentando fazer com que a pessoa fique constrangida. Acredito que tenha um momento pra se chamar a atenção, mas que precisa ser feito com cautela. Acredito que na universidade tenha bastante disso ainda. São situações constrangedoras, de falar alto com o aluno diante de uma equipe de saúde. Até usar algumas palavras ofensivas: nossa, mas você é burro, você não aprendeu que não pode fazer isso. Então por estar demorando um pouquinho, por ser um processo de 
aprendizado, as vezes a gente se sente um pouco inseguro. Preparar uma medicação acaba sendo um pouco mais demorado. O modo com que você vai preparar, tomando um pouco mais de cuidado e aí o professor repreende, chama a atenção, usa palavras ruins que deixam o aluno constrangido e é bem ruim. Às vezes um erro que não era assim tão grave, mas que acabou maximizando tanto e deixou o aluno extremamente intimidado. (E7)

De acordo com os sujeitos do estudo, a hierarquia de poder existente entre os corpos docente e discente da instituição favorece a ocorrência de maus-tratos. Os alunos expuseram seus sentimentos de menos-valia, humilhação e até de incapacidade no desenvolvimento das tarefas diante das avaliações, por vezes, pejorativas dos seus mestres. Manifestaram inconformismo com atitudes constrangedoras e agressivas de alguns professores em situações de ensino-aprendizagem. Consideraram ser um contrassenso o professor, por ser experiente, exercer a função de educador e formador, e servir de modelo, maltratar e expor seus aprendizes na frente de colegas, pacientes e equipes de saúde.

É esperado que o estudante desenvolva capacidades e competências desejáveis a carreira escolhida. Para mensurar o adquirido, é submetido a um processo avaliativo contínuo. Isto gera conflitos com seus pares e com quem ensina. Entre os colegas identificaram a competição. Já com o docente, por esse ter a responsabilidade de avaliar o aprendizado e atribuir uma nota, pode ser criada uma relação que não representa o real e que pode culminar com avaliações distorcidas. $\mathrm{Na}$ opinião dos entrevistados, o docente pode usar de retaliação quando contrariado ou questionado em seu saber. Já o aluno, tende a se retrair com receio de ao expor sua opinião ou descontentamento com algo, ser alvo da desforra do professor que o avalia com conceito menor.

A literatura corrobora com os resultados do nosso estudo ao revelar o uso de coerção pelos docentes por meio de notas punitivas ${ }^{(5,8,15,17)}$. Essa atitude ou forma de controle, vista como natural no ambiente universitário para punir aqueles que discordam ou pensam diferente, acontece de forma subjetiva e pode desencadear ansiedade, angústia, medo, insegurança, descrédito, desânimo, conformismo, depressão e reações agressivas nos estudantes. Como resultado a baixa motivação, podem ocorrer absenteísmos, atrasos, reprovações e desistências, identificadas como reais e contraproducentes ${ }^{(5,8)}$. Os alunos podem, por outro lado, reagir assumindo papel passivo, dependente e submisso, como relatado pelas entrevistadas e descrito na literatura $^{(8,15,17) \text {. }}$

Esta forma de poder exercida pelos professores pode contribuir para o desenvolvimento de sujeitos não críticos, pois os alunos acabam admitindo e assumindo as regras impostas por estes profissionais e pela instituição escolar sem questionamentos ${ }^{(15-16)}$.

A questão de nota, as vezes eu sinto que os professores também cometem violência. A gente não pode contradizer nada, usar argumento contrário, argumentar alguma coisa que ele tenha dito, especialmente com medo da avaliação. Antes de terminar a disciplina eu fico com medo de conversar com o professor porque ele não fechou a nota. Ele tem o poder e eu acabo ficando submissa com medo de ser vítima de uma agressão diferente através de uma nota baixa. (E7)

Têm muitos alunos, colegas que tentam passar o outro pra trás. Vale tudo pra ser o melhor. Um quer comer a cabecinha do outro, quer ser melhor, prejudicar o outro, muito egoísmo, muita falta de caráter. (E6)

Algumas das alunas relataram terem sofrido maustratos dos profissionais da equipe de enfermagem nos campos de estágio, manifestados pela falta de receptividade, indiferença, não aceitação e ausência de colaboração no seu processo de aprendizagem. De acordo com a literatura, tais atitudes ocorrem em função da desigualdade de poder entre os profissionais e o corpo discente $^{(1,6)}$. Em um estudo as estudantes apontaram 4 níveis de injustiças: "somos indesejadas e ignoradas", "não acreditam e desconfiam de nossas avaliações/achados ao examinar os pacientes", "nós éramos injustamente acusadas" e "fui humilhada publicamente" ${ }^{\prime(6)}$.

Os docentes, por sua vez, não conseguem policiar todas as situações de maus-tratos contra seus alunos. No entanto, é esperado que estimulem os estudantes a reportarem as ocorrências e que não expliquem as atitudes das enfermeiras como sendo fruto de sobrecarga ou estresse. É indicado, também, incluir no currículo de graduação em enfermagem o tema abuso no ambiente de trabalho para preparar os estudantes para o inevitável(6).

Em alguns lugares a gente é bem recebida, o pessoal tem uma interação legal, mas tem lugares que a pessoa entorta o nariz, faz cara feia, como se você tivesse lá atrapalhando. Na verdade você ta tentando aprender, e aí 
como eles sabem mais, talvez eles poderiam ajudar mais, aí eles cruzam os braços e eles não colaboram. (E1)

A maioria dos enfermeiros não se importa, eles são indiferentes. (E4)

Há setores que eu acho que são muito conturbados, a equipe não aceita alunos, é, então fica muito difícil. Mas de modo geral eu acho que é positivo também. (E9)

\section{Participação como vítima ou perpetradora}

As estudantes revelaram terem sido vítimas de violência por professores e colegas. Queixaram-se de cobranças, pressões, perseguições, constrangimentos, humilhações e tratamentos pejorativos por parte de professores. Já seus colegas, zombavam, ofendiam, menosprezavam e faziam intrigas. Uma das participantes relatou situação em que ao repetir disciplina por reprovação foi interpelada por colega questionando sua participação e ocupação do tempo do professor, em atitude individualista que configura competição entre pares $^{(8)}$.

Resultados de pesquisas mostram que estudantes universitários da área da saúde podem ser vítimas de comportamentos hostis, abusivos, coercivos ou humilhantes cometidos tanto por colegas quanto por docentes e outros profissionais envolvidos no ensino. Dentre as formas de abuso a maioria é do tipo verbal e acadêmico $^{(5,14,18-21)}$.

Como consequência das agressões sofridas e também citado na literatura, as participantes do nosso estudo sentiram-se ofendidas, diminuídas, desencorajadas, magoadas, deprimidas e desestimuladas ${ }^{(15,20)}$. Uma das entrevistadas referiu ter buscado apoio de amigos para superar estas ocorrências. De acordo com pesquisas há uma tendência a naturalização de maus-tratos no meio acadêmico. Os estudantes acabam por ignorar tais situações por temerem possíveis retaliações e, assim, não as denunciam ${ }^{(5,14,18-20)}$.

Já fui ofendida, me senti diminuída por uma professora no segundo ano. Ela cobrava mais de mim, me perseguia, ficava muito em cima, não aceitava que eu errasse, acabava comigo. Essa professora me desincentivou muito. Eu quase tranquei meu curso por causa dela, mas eu me apoiei em amigos que falaram que eu tinha que superar e que os obstáculos iam ser daí pra pior. Então eu resolvi dar a volta por cima. (E6)

Um colega falou pra mim que por eu ser repetente tinha a obrigação de saber as coisas e não podia ocupar a professora. É uma violência moral, uma ofensa, uma agressão. (E10)
Você vê a pessoa falar de você, cochichar, fofocar, zombar de você. Isso me afetou muito. (E12)

Já fui chamada de filhinha no estágio e não gostei. (E13) No campo de estágio às vezes tem aquelas palavras que acabam te humilhando, é, constrangedor. Dependendo da forma como é dito, te magoa muito, deprime, faz com que você pare e pense: o que estou fazendo aqui, vale a pena continuar? Isso desestimula muito o aluno. (E9)

As alunas perceberam que foram agentes de violência quando zombaram, expressaram-se de forma inconveniente, tentaram impor sua opinião ou foram negligentes. O cansaço, a impaciência, a intolerância, o estresse, a sobrecarga, a reação aos problemas pessoais, a intimidade e a banalização da violência foram apresentadas como justificativa para estas atitudes. A naturalização do fenômeno da violência no ambiente acadêmico é confirmada em outros estudos ${ }^{(5,15,18)}$.

Às vezes a gente "zoa", fala: como você está gordinha ou nossa, você está magrela, passando fome. Isso com quem eu tenho mais intimidade. (E5)

Acho que algumas vezes eu provoco sim, qualquer um pode se alterar. Eu naturalmente sou muito explosiva. Já cheguei quase a descontar o que eu estava sentindo no paciente, fiz tudo meio de mau gosto, sem vontade e acho que ele e alguns colegas perceberam. Mas eu tento ao máximo não fazer isso. (E6)

Acredito que talvez eu desperte, cause violência com palavras. Uma maneira de violentar é não querer ouvir, querer impor a sua opinião, não dar chance pra outra pessoa falar o que ela pensa e tudo mais por uma questão boba, por discussão do dia a dia. Este momento de estresse, de sobrecarga, que acaba explodindo. Mas, sempre tentei concertar, conversar. (E7)

A gente infelizmente não consegue separar os nossos problemas pessoais, ainda mais quando a gente esta cansado, estressado, impaciente, intolerante, com muita dificuldade. Talvez eu não me expresse bem e chateie a pessoa. (E11)

\section{Razões para a ocorrência da violência}

$\mathrm{Na}$ opinião das participantes, entre as razões que justificariam o aparecimento de situações de violência no ambiente acadêmico, o estresse e o cansaço foram apontados como comuns a docentes, profissionais e estudantes.

No que diz respeito aos professores, acreditam que características pessoais como insatisfação pessoal e profissional, traços de personalidade, aliados a 
competição acadêmica, constituem fatores que os levam a ser agressivos e humilhar para, por vezes, se sentirem superiores.

A universidade constitui local favorável para a competição. Entre os docentes esta se dá por prestígio e reconhecimento acadêmico, cargos, publicações e obtenção de financiamentos para pesquisas ${ }^{(22)}$. Comumente são descritos comportamentos abusivos, hostis ou humilhantes que tem como perpretadores pessoas com posição superior ou maior tempo de instituição, dando início a um ciclo vicioso onde a prática violenta é transmitida de uma geração para a outra(14,2223).

Há, ainda, dados que mostraram uma correlação significativa entre frequência de reuniões e relatos de abusos $^{(23)}$. Por sua vez, a exposição a maus-tratos como grosserias de estudantes, violência dos colegas e abuso de poder por administradores pode gerar danos físicos, psicológicos e emocionais nos professores ${ }^{(24)}$. Pode, também, influenciar sua permanência nas instituições de ensino e facilitar atitudes agressivas desses para com seus alunos $^{(23)}$.

Ainda, de acordo com as estudantes, os docentes não percebem a sobrecarga do curso, não reconhecem as diferenças entre os alunos, não toleram quando esses não correspondem as suas expectativas, ficam distantes, não oferecem apoio, são autoritários e avessos a questionamentos e críticas. Esses achados encontram respaldo em artigo que revela que as relações assimétricas no contexto universitário, marcadas pelo poder e seu uso, produzem um manejo inadequado do processo de ensino-aprendizagem pelos docentes, ao originar uma verticalização que não aproxima os professores dos sujeitos interessados no aprendizado(15).

A qualidade da relação afetiva estabelecida entre o professor e o aluno parece favorecer a aprendizagem. Contudo, tem sido muitas vezes negligenciada tanto na prática da sala de aula quanto na formação docente ${ }^{(7)}$.

Uma das entrevistadas mencionou sua percepção quanto à dificuldade na inserção de professores e alunos nos campos de estágio. Atitudes de cobranças, críticas e postura de não ajuda dos profissionais dos serviços explicam sua constatação. Os professores pressionados por esta circunstância acabam descontando nos alunos. Estes comportamentos dos profissionais são difíceis de definir devido a sua natureza subjetiva e tolerância variável entre os indivíduos. Muitos estudantes os aceitam como "rito de passagem", somente para mimetizar e repetir o comportamento mais tarde em suas carreiras, ou seja, "as enfermeiras aprendem a comer as jovens iniciantes e umas as outras, como parte de sua

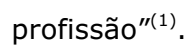

Depende do temperamento do professor, do que está acontecendo com ele. Acaba descontando de alguma forma nos alunos. Alguns quererem ser exigentes e acabam tendo atitudes violentas. (E3)

Eu não sei muito bem, mas às vezes é insatisfação consigo próprio, necessidade de ferir o outro. Humilhar o outro pra se sentir superior. (E1)

Acho que é cansaço. Acho que não gosta muito da área em que trabalha, caiu lá por acaso. (E2)

Entre os docentes é mais pela competitividade que há no meio acadêmico. Falta de compreensão das nossas diferenças. Os professores são muito autoritários, acham que são melhores, não há humildade entre eles e com a gente. Ao invés de resolver através de uma conversa, preferem impor o que acham e não aceitam o que o outro pensa. (E8)

Eu creio que os professores têm a melhor intenção quanto ao nosso aprendizado, pra passar tudo pra gente, mas às vezes eles não compreendem a nossa dificuldade, eles não compreendem que cada um é um, que tem uns que aprendem rápido e outros pegam devagar. Eles acham que tem que ser tudo no tempo deles e não é assim. Até por isso que a gente esta aqui pra aprender e cabe a eles ter paciência com a gente, porque se você não tem paciência você não serve para ser professor, porque exige uma paciência bem grande, eu acho. (E6)

Os professores se acham detentores do saber, inatingíveis, ficam distantes, não percebem ou não apóiam a gente. (E7)

Quando os alunos não estão correspondendo às expectativas do docente ele explode. Os profissionais dos serviços às vezes não ajudam os alunos e, muitas vezes não incluem os professores. Todas as ações dos alunos passam a ser visadas: se pegamos muitas luvas reclamam que estamos acabando com o dinheiro do serviço; se pegamos poucas é porque não temos higiene, vamos passar infecção para o hospital inteiro e não temos noção do que fazemos. O professor fica com a cabeça cheia e acaba descontando na gente. Mas para uma pessoa graduada, acho que o mínimo é sentar e conversar. (E4) É muito estresse por parte dos profissionais e muita preocupação. Eles acabam descontando. (E13)

Com relação aos alunos, mencionaram a sobrecarga de atividades com falta de tempo livre para cuidarem de si mesmas, os diferentes graus de comprometimento na execução das tarefas, a concorrência despertada com a 
proximidade do término do curso como possíveis causas para a ocorrência da violência. Além dessas motivações, acreditam que a amizade facilita o zombar e que a vaidade, o orgulho e a inveja despertam sentimentos de superioridade e alimentam a competição. A esse respeito, estudos apontam que preocupações, sobrecarga de atividades acadêmicas teóricas e práticas e relacionamentos interpessoais entre discentes são estressores que podem desencadear atitudes agressivas nos estudantes ${ }^{(17,25)}$.

A gente não tem onde extravasar, não tem momento livre pra poder ficar com nossa família, sair pra bater papo com amigos e praticar esportes. Tem uma sobrecarga, um monte de compromissos, de coisas que precisa fazer. Vem o estresse e você acha que não vai conseguir dar conta daquilo. Acaba descontando em quem não tem nada a ver com isso, acaba levando esses problemas pra casa, deixando de cuidar de você mesmo. Eu acredito que exista esta violência contra nós mesmos, este descuido. (E7) Acho que é multifatorial, que existem várias causas. Percebo que o cansaço, o estresse, o excesso de atividades, a concorrência por estarmos nos últimos anos, a disputa, a diferença com que cada um assume as responsabilidades nas atividades. Essas situações levam a brigas, violências psicológicas e verbais. (E11)

Acho que a competitividade, o estresse, a inveja. (E12)

Porque é amiga da pessoa acha que é normal brincar, zoar com a pessoa. (E5)

Quanto à violência entre alunos, eu creio que seja vaidade, orgulho, querer ser melhor que o outro. (E6)

O ajustamento do educando pode se tornar danoso, quando ocorre a discriminação, o poder sobre o outro ou fraca capacidade demonstrada pelos profissionais de criar mecanismos justos e democráticos de gestão na vida escolar, gerando, assim, as várias formas de violência presentes nas relações estabelecidas no contexto universitário(15-16).

\section{REFERÊNCIAS}

1. Hinchberger PA. Violence against female student nurses in the workplace. Nurs Forum. 2009;44(1):37-46.

2. Costa MC, Silva EB, Jahn AC, Dalmolin IS, Santos M, Silva CM. Representações sociais da violência escolar na expressão de jovens estudantes. Rev. Eletr. Enf. [Internet]. 2012 [acesso em:

\section{CONSIDERAÇÕES FINAIS}

Os estudantes passam a maior parte do seu tempo no ambiente acadêmico. Desse modo, seria desejável que esse local propiciasse ao aluno experiências estimulantes e agradáveis, onde pudesse fazer reflexões, análises críticas, descobertas e fossem estimuladas discussões de forma cooperativa com seus pares, professores e outros personagens envolvidos no processo de ensinoaprendizagem. Contudo, a realidade encontrada nas instituições de ensino superior não é a idealizada. As interações e relacionamentos no ambiente universitário, seja em sala ou em campo de estágio, sofrem influências das diferenças de poder. E, tal qual um microcosmo da sociedade, emergem situações de violência de vários tipos.

Os achados do nosso estudo permitiram conhecer a percepção de acadêmicos de enfermagem sobre a ocorrência de violência no ambiente universitário, sua participação como vítima ou perpetrador e sobre suas possíveis causas. Confirmamos a desigualdade de poder $\mathrm{e}$ sua relação com a ocorrência de diferentes tipos de violência e a tendência na naturalização desses.

No sentido de garantir um ambiente de aprendizado é necessário criar um sistema que facilite a denúncia de abusos e ofereça apoio às vítimas. Para tanto é importante que as instituições invistam em programas de intervenção voltados para a conscientização acerca do tema, melhoria das relações acadêmicas e, consequentemente, a estratégias preventivas. A inclusão do tema violência nas grades curriculares pode também auxiliar neste processo. Os professores, por sua vez, necessitam ser conscientizados sobre a temática da violência e sua participação como perpetrador ou vítima. Como educadores e modelos para futuros profissionais, devem buscar conhecimento sobre o tema e participar de cursos de capacitação, treinamento e qualificação que visem instrumentalizá-los para o enfrentamento da violência no ambiente acadêmico. Ao criar estes mecanismos, os estudantes podem ser preparados tanto para o reconhecimento e manejo de situações de maus-tratos no meio acadêmico, como para o atendimento de vítimas de diferentes formas de violência em sua atuação profissional.

05 ago 2014];14(3):514-22. Disponível em:

http://dx.doi.org/10.5216/ree.v15i4.18905.

3. Scherer ZAP, Scherer EA. Identificação dos pilares da

educação na disciplina integralidade no cuidado à saúde. Rev Esc Enferm USP. 2012;46(4):985-93. 
4. Moreno-Cubillos CL, Sepúlveda-Gallego LE. Violence and discrimination against nursing students in a Colombian public university. Invest Educ Enferm. 2013;31(2):226-33.

5. Miranda MIF, Oliveira TR, Barreto PDT, Ferriani MGC, Santos MAM, Neto DL. Conduta de acadêmicos de uma universidade da região amazônica frente ao bullying. Enfermagem em Foco. 2012;3(3):114-8.

6. Thomas SP, Burk R. Junior nursing students' experiences of vertical violence during clinical rotations. Nurs Outlook. 2009;57(4):226-31.

7. Ribeiro, ML. A afetividade na relação educativa. Estud. psicol. $2010 ; 27(3): 403-12$.

8. Kienen N, Botome SP. As relações entre controle sobre o trabalho e condições de saúde de alunos universitários. Interação em Psicologia. 2003;7(2):11-22.

9. Minayo MCS. O desafio do conhecimento: pesquisa qualitativa em saúde. 8th ed. São Paulo: Hucitec; 2010.

10. Fontanella BJB, Ricas J, Turato ER. Amostragem por saturação em pesquisas qualitativas em saúde. Cad. Saúde Pública. 2008;24(1):17-27.

11. Bardin L. Análise de Conteúdo. Lisboa: Edições 70; 2004. 12. Costa SM, Dias OV, Dias ACA, Souza TR, Canela JR. Trote universitário: diversão ou constrangimento entre acadêmicos da saúde? Rev bioét. 2013;21(2):350-8.

13. James A, Chapman Y. Preceptors and patients - the power of two: nursing student experiences on their first acute clinical placement. Contemp Nurse. 2010;34(1):34-47.

14. Iftikhar $R$, Tawfiq $R$, Barabie $S$. Interns' perceived abuse during their undergraduate training at King Abdul Aziz University. Adv Med Educ Pract 2014;5:159-66.

15. Cruz GV, Pereira WR. Different configurations of violence in pedagogical relationships between teachers and students of higher education. Rev Bras Enferm. 2013;66(2):241-50.

16. Ferro JP, Araújo EL. Algumas reflexões sobre o fenômeno da violência escolar. Interfaces da educ. 2010;1(2):68-78.

17. Cooper JRM, Walker J, Askew R, Robinson JC, McNair M. Students' perceptions of bullying behaviours by nursing faculty. Issues in Educational Research. 2011;21(1):1-21.

18. Paredes, OL, Sanabria-Ferrand PA, González-Quevedo LA, Rehalpe SPM. "Bullying" en las facultades de medicina colombianas, mito o realidad. Revista Med. 2010;18(2):161-72. 19. Fnais N, Soobiah C, Chen MH, Lillie E, Perrier L, Tashkhandi $M$, et al. Harassment and discrimination in medical training: a systematic review and meta-analysis. Acad Med.

2014;89(5):817-27.

20. Soler VM, Menequesso BM, Santos CEJ, Felice KZ. Fenômeno bullying em instituição de ensino superior. CuidArte Enfermagem. 2009;3(1):11-8.

21. Zayed M, Ahmed D, Halawa EF. Pattern and predictors of interpersonal violence among adolescent female students in Egypt. J Community Health. [Internet]. 2014 [acesso em: 27 jun 2014];39:1-7. Disponível em:

http://link.springer.com/article/10.1007/s10900-014-9855-5. 22. Caran VCS, Secco IAO, Barbosa DA, Robazzi MLCC. Assédio moral entre docentes de instituição pública de ensino superior do Brasil. Acta Paul Enferm. 2010;23(6):737-44.

23. Beckmann CA, Cannella BL, Wantland D. Faculty perception of bullying in schools of nursing. J Prof Nurs. 2013;29:287-294. 24. DalPezzo NK, Jett KT. Nursing faculty: a vulnerable population. J Nurs Educ. 2010;49(3):132-6.

25. Silva VLS, Chiquito NC, Andrade RAPO, Brito MFP, Camelo $\mathrm{SHH}$. Fatores de estresse no último ano do curso de graduação em enfermagem: percepção dos estudantes. Rev. enferm. UERJ. $2011 ; 19(1): 121-6$.

Artigo recebido em 08/03/2013.

Aprovado para publicação em 05/06/2014.

Artigo publicado em 31/03/2015. 